\title{
Rola badania PET w leczeniu raka szyjki macicy w doniesieniach na 3rd ESTRO Forum 2015
}

\section{Role of PET in the treatment of cervical cancer in reports presented at the 3rd ESTRO Forum 2015}

\author{
Ewa Burchardt ${ }^{1}$ \\ ${ }^{1}$ Oddziat Radioterapii i Onkologii Ginekologicznej z Izbą Przyjęć
}

\section{Streszczenie}

W 2015 roku w Barcelonie odbyła się kolejna konferencja naukowa Europejskiego Towarzystwa Radioterapii Onkologicznej (ESTRO). Szczególną uwagę należy poświęcić doniesieniom naukowym dotyczącym roli badań obrazowych z dziedziny medycyny nuklearnej. Jest to temat o coraz większym znaczeniu, który w obecnej chwili jest w centrum zainteresowania wielu specjalistów zajmujących się leczeniem onkologicznym. Także w ginekologii onkologicznej wielu autorów prac przedstawiło swoje badania z zakresu roli badania PET w leczeniu raka szyjki macicy.

\begin{abstract}
:
In 2015, the conference of the European Society of Radiation Oncology (ESTRO) was held in Barcelona. Particular attention should be paid to reports in the field of imaging in nuclear medicine. This is an issue of growing importance that attracts attention of many specialists in cancer treatment. There were also many papers related to the role of PET- CT in cervical cancer treatment.
\end{abstract}

Stowa kluczowe: rak szyjki macicy; FDG-PET; FLT-PET; radioterapia

Keywords: cervical cancer; FDG-PET; FLT-PET; radiotherapy

Adres do korespondencji

dr n. med. Ewa Burchardt

Kierownik Pracowni Hipertermii

Oddział Radioterapii i Onkologii Ginekologicznej z Izbą Przyjęć

Wielkopolskie Centrum Onkologii,ul. Garbary 15, 61-866 Poznań, Polska

e-mail: ewa.burchardt@wco.pl 


\section{Wstęp}

Naświecieodnotowujesię50oooonowychzachorowańnarakaszyjkimacicyrocznie,coplasujetennowotwór na czwartym miejscu wśród kobiet [1]. W Polsce w 2012 roku raportowano 2783 nowo zdiagnozowanych chorych [2]. W 2010 roku zachorowalność na raka szyjki macicy w Polsce była około 15\% wyższa niż średnia w krajach zachodniej Europy [3].

Obecna klasyfikacja FIGO zdefiniowana przez International Federation of Gynecology and Obstetrics nadal opiera się na badaniu fizykalnym pacjentki. To może prowadzić do nieadekwatnego określenia zaawansowania choroby. Klasyfikacja ta nie włącza oceny węzłów chłonnych i przerzutów odległych, które są ważnymi negatywnymi czynnikami prognostycznymi [4]. Właściwa ocena rozległości choroby warunkuje prawidłowe leczenie. Pomimo lepszej klasyfikacji do leczenia i lepszej jakości leczenia (radiochemioterapia i $3 \mathrm{D}$ brachyterapia), lokoregionalna kontrola stanowi duże wyzwanie. Zgodnie z wytycznymi National Comprehensive Cancer Network (NCCN) badanie pozystronowa tomografia emisyjna- (PET-CT) stanowi alternatywę dla badania tomografem komputerowym (CT w diagnostyce raka szyjki macicy).

W porównaniu do zabiegu operacyjnego jest nieinwazyjną opcją w ocenie zaawansowania choroby. Dostarcza istotnych informacji dotyczących biologicznych właściwości komórek guza, takich jak utlenowanie, proliferacja, metabolizm. W literaturze ocenia się, że około 15-30\% nowo zdiagnozowanych chorych z rakiem szyjki macicy ma przerzuty w węzłach okołoaortalnych (LN+) [5][6]. Badania prospektywne porównujące pozytywny wynik węzłów chłonnych w badaniu PET-CT z fluorodeoxyglukoza (FDG) i pozytywny wynik histopatologiczny uzyskany w lymfadenektomii demonstrują czułość i specyficzność badania FDG PET-CT odpowiednio na 84\% i 95\% [7][8][9]. Wykonanie FDG PET przed leczeniem poprawia wykrycie przerzutów poza miednicą [10] [11] [12]. W przedstawionej na konferencji ESTRO Forum 2015 pracy z Włoch "The role of 18F-FDG PET in pretreatment evaluation of cervical carcinoma”, w której włączono do badania 93 chore, analizowano wartość skojarzonego badania diagnostycznego FDG PET-CT i MRI. Połączenie dwóch technik obrazowania umożliwia wykrycie większej liczby LN+ w miednicy, ponadto FDG PET przydatne jest w ocenie węzłów okołoaortalnych (PALN).

Badanie PET- CT odgrywa bardzo ważną rolę w obserwacji po leczeniu. Zgodnie z pracą Grigsby et al. [13][14] przeżycia (OS - overall survival) 5-letnie korelują ściśle z wychwytem znacznika w okresie followup. 5-letnie OS dla chorych z całkowitą odpowiedzią metaboliczną w guzie obserwowana w badaniu PET wynoszą 80\%, dla chorych z obserwowanym wychwytem FDG w guzie po leczeniu wynoszą 32\% i gdy zaobserwowano nowe miejsca z aktywnością FDG w okresie obserwacji po leczeniu 5-letnie OS wynoszą o\%.

Kolejnym istotnym elementem jest prawidłowa ocena aktywności metabolicznej i wielkości guza w badaniu PET, która odgrywa ważną rolę w planowaniu radioterapii i jest głównym czynnikiem decydującym o prognozie [15][16]. Wartość wskaźnika SUV max (standaryzowana wartość wychwytu) jest wyższa w raku płaskonabłonkowym i rakach niskozróżnicowanych, niż w innym rozpoznaniu histopatologicznym. Stanowi niezależny czynnik zgonu z powodu raka szyjki i niezależny czynnik niewyleczenia. Wartość SUV węzłów chłonnych jest czynnikiem ryzyka wznowy, a wartość SUV max guza to predykcyjny biomarker ryzyka zajęcia węzłów chłonnych.

PET- CT jest wykorzystywany w planowaniu leczenia. Wyniki tego badania nawet do 30\% wpływają na zmianę decyzji terapeutycznej. Dotyczą albo zastosowania neoadjuwantowej chemioterapii, gdy jest obecny rozsiew choroby lub zmiany pola terapeutycznego. Podczas planowania leczenia następuje rozszerzenie pól radioterapeutycznych o regiony węzłów okołoaortalnych oraz podwyższenie dawki na rejony aktywne metabolicznie i podejrzane o rozrost nowotworowy. Takie planowanie opiera się o fuzje badań obrazowychzarówno TK do planowania leczenia jak i FDG PET -CT [16] [17]. W pracy ośrodków z Danii i Holandii „Impact of lymph node dose on nodal control in patients with locally advanced cervical cancer" analizowano 140 chorych pod kątem korelacji między dawką całkowitą, a odpowiedzią na leczenie przerzutowych węzłów chłonnych. Schemat planu leczenia w obu ośrodkach przedstawiono w tab. 1. Status węzłów chłonnych definiowany był na podstawie badania rezonansem magnetycznym (MRI) i PET-CT przed leczeniem. Odpowiedź na leczenie oceniana była w badaniu MRI i PET-CT odpowiednio w 3. i 12 m-cu po leczeniu. Stwierdzono brak wpływu dawki mniejszej lub większej od 6o Gy (Fischer's exact test, p=0.6) i brak wpływu objętości węzła przerzutowego. Wznowy lokalizowane były poza obszarem PTV (ang.planning target volume), głównie w rejonie węzłów chłonnych około aortalnych, ktore nie były objęte pierwotnym planem leczenia. 
Tabela 1. Schemat leczenia

\begin{tabular}{|c|c|c|}
\hline & Szpital 1 & Szpital 2 \\
\hline $\begin{array}{c}\text { Teleradioterapia na węzły } \\
\text { elektywne (PTV -E) }\end{array}$ & 45 Gy w 25 frakcjach & $\begin{array}{c}\text { 45 Gy w 25 frakcjach ( pacjenci } \\
\text { bez zajętych węzłów chłonnych) } \\
\text { 50Gy w 30 frakcjach (pacjenci } \\
\text { z zajętymi węzłami chłonnymi) }\end{array}$ \\
\hline $\begin{array}{c}\text { Teleraditerapia boost na zajęte } \\
\text { węzły (PTV - N) }\end{array}$ & $\begin{array}{c}\text { Sekwencyjnie 5 lub 7 frakcji } \\
\text { po 2 Gy }\end{array}$ & SIB - 60 Gy w 30 frakcjach \\
\hline BT na HR-CTV & Opcja 1: PDR w 2 frakcjach 19,2 Gy \\
Opcja 2: HDR 4 x 7 Gy & $\begin{array}{c}\text { Opcja 1: PDR (wolne węzły) w 2 } \\
\text { frakcjach 17,5 Gy w 20 pulsach } \\
\text { Opcja 2: (zajęt węzły) PDR 2 } \\
\text { frakcje po 15 Gy w 20 }\end{array}$ \\
\hline
\end{tabular}

PTV-E lub PTV N - Plannig Target Volume elektywny (E) lub węzłowy (N), boost - dodawkowanie, BT - brachyterapia, HR CTV - high risk Clinical Target Volume - obszar tarczowy wysokiego ryzyka, SIB - simultaneous intergrated boost - jednoczasowy boost

Ograniczenia związane z użyciem tylko FDG wiążą się z jego podwyższonym gromadzeniem w stanach zapalnych i w każdej komórce wykorzystującej glukozę jako materiał energetyczny (np. w tkance mózgowej). W nowoczesnej medycynie wykorzystującej obrazowanie molekularne dostępne są radionuklidy dostarczające różnych informacji o funkcji ibiologii guza. Jednym z najbardziej obiecujących jest marker cyklu komórkowego. Proliferacja komórki jest kluczowym aspektem rozwoju i wzrostu guza. 18 (FLT) -30-Fluoro-30-deoxyL-thymidine wydaje się być specyficznym dla guza znacznikiem. Poziom 18F-FLT jest proporcjonalny do aktywności kinazy tymidynowej i do innych wskaźników proliferacji, jak np. Ki-67 [18]. FLT nie gromadzi się w stanach zapalnych i umożliwia obrazowanie bardziej agresywnych obszarów w guzie nowotworowym [19]. Praca dotycząca tego zagadnienia „Porównanie badania FLT PET-CT i FDG PET-CT przed leczeniem u pacjentek z rozpoznanym nowotworem raka szyjki macicy” z Wielkopolskiego Centrum Onkologii wybrana została do prezentacji w ramach ESTRO Young Scientists [20]. Celem była ocena przydatności badania FLT PET w ocenie raka szyjki macicy i przerzutów do węzłów chłonnych w porównaniu do badania FDG PET oraz analiza parametrów badania FLT PET i FDG PET. Chore zakwalifikowane do radiochemioterapii przed rozpoczęciem leczenia, po wyrażeniu zgody, miały wykonywane 2 badania PET CT ze znacznikiem FLT i w odstępie 1 tygodnia ze znacznikiem FDG. Badanie zrealizowano w latach $2012-2014$. Zakwalifikowano 28 chorych z histopatologicznie rozpoznanym rakiem szyjki macicy, z zaawansowaniem klinicznym FIGO IIIII, średnia wieku 52 +/-12 (SD) lata. Wykonywano rutynowo morfologię krwi, pobierano materiał z pochwy celem oceny kolonizacji bakteryjnej przed leczeniem. U wszystkich chorych wykazano wzrost wychwytu znacznika FLT i FDG w guzie pierwotnym. SUV max i SUV mean były generalnie niższe dla FLT-GTV niż

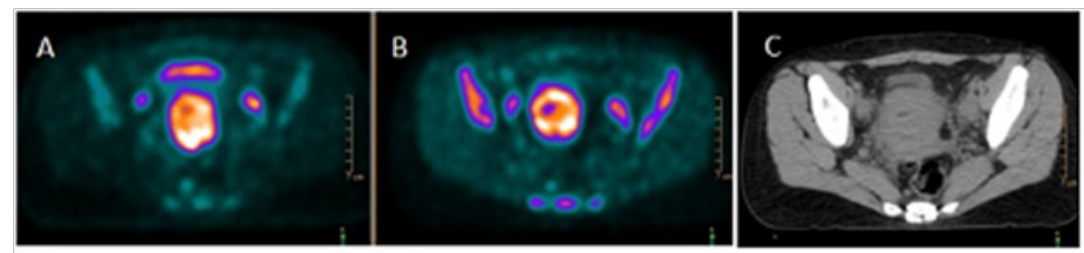

D

$\mathrm{E}$

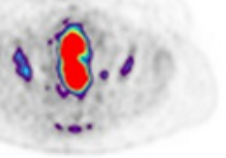

Rysunek 1. Przykładowe porównanie badania PET - CT u tej samej pacjentki ze znacznikiem FDG (A i D) oraz PET- CT ze znacznikiem FLT (B i E). Referencyjny obraz badania CT (C). 


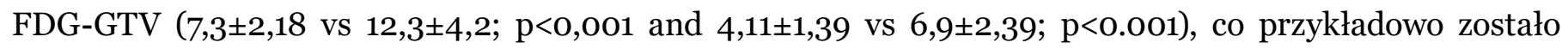
zilustrowane na ryc. 1 .

Jednakże u 3 chorych wartości SUV dla FLT-GTV były wyższe, niż dla FDG-GTV. Nie wykazano istotnych

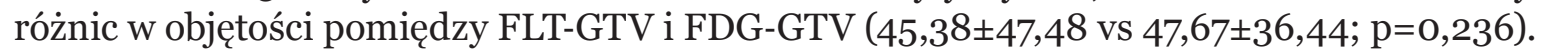

Wykazano korelację pomiędzy FLT objętością vs FDG objętością $(\mathrm{R}=0,7, \quad \mathrm{p}<0,001)$ i słabą korelację między FDG SUV max i poziomem hemoglobiny ( $\mathrm{R}=0,397, \quad \mathrm{p}=0,03)$. Analiza innych klinicznych i metabolicznych parametrów przedstawionych $\mathrm{w}$ tab. 2 była nieistotna statystycznie.

Tabela 2. Korelacja R-Spearman klinicznych I metabolicznych parametro

\begin{tabular}{|c|c|c|c|}
\hline & $\mathrm{n}$ & R - Spearman & $\mathrm{p}$ \\
\hline FLT Volume \& FDG SUVmax & 28 & 0,061 & 0,757 \\
\hline FLT Volume \& FDG Volume & 28 & 0,716 & $<0,001$ \\
\hline FLT Volume \& FLT SUVmax & 28 & 0,063 & 0,750 \\
\hline FLT SUVmax \& FDG SUVmax & 28 & 0,264 & 0,174 \\
\hline FDG Volume \& FDG SUVmax & 28 & $-0,078$ & 0,693 \\
\hline FDG Volume \& FLT SUVmax & 28 & 0,056 & 0,776 \\
\hline $\mathrm{Hgb}[\mathrm{mmol} / \mathrm{L}]$ \& FLT SUVmax & 28 & 0,014 & 0,945 \\
\hline $\mathrm{Hgb}[\mathrm{mmol} / \mathrm{L}]$ \& FLT Volume & 28 & $-0,049$ & 0,805 \\
\hline $\mathrm{Hgb}[\mathrm{mmol} / \mathrm{L}] \& \mathrm{FDG}$ SUVmax & 28 & $-0,397$ & $<0,001$ \\
\hline $\mathrm{Hgb}[\mathrm{mmol} / \mathrm{L}]$ \& FDG Volume & 28 & $-0,510$ & 0,102 \\
\hline Neu 「G/L] \& FLT SUVmax & 28 & $-0,165$ & 0,401 \\
\hline Neu 「G/L $\&$ FLT Volume & 28 & 0,167 & 0,394 \\
\hline Neu 「G/L† \& FDG SUVmax & 28 & $-0,276$ & 0,155 \\
\hline Neu 「G/L〕 \& FDG Volume & 28 & 0,216 & 0,269 \\
\hline WBC 「G/L] \& FLT SUVmax & 28 & $-0,201$ & 0,306 \\
\hline WBC 「G/L〕 \& FLT Volume & 28 & 0,033 & 0,866 \\
\hline WBC [G/L] \& FDG SUVmax & 28 & $-0,162$ & 0,410 \\
\hline WBC 「G/L门 \& FDG Volume & 28 & 0,009 & 0,965 \\
\hline
\end{tabular}

Nie wykazano różnicy w wychwycie znacznika u chorych z zajęciem węzłów chłonnych czy wyższym stopniem FIGO. CTV zawsze zawierał zarówno FLT jak i FDG GTV. U 3 pacjentek po badaniu FDG PET zmieniono decyzję i włączono neoadjuwantową chemioterapię, u jednej chorej w trakcie leczenia rozwinęły się przerzuty do OUN.

Inne dostępne radionuklidy to metionina, F- dihydroksyfenyloalanina przedstawiające syntezę białek i transport aminokwasów. F- mizonidazol (FMISO) i Cu-ATSM kumulują się w tkance o nasilonej hipoksji. Zidentyfikowanie tych obszarów jest bardzo istotne w prowadzeniu leczenia radioterapeutycznego, ponieważ hipoksja guza wiąże się z opornością na leczenie. Można dzięki temu zidentyfikować pacjentów, którzy wymagają bardziej intensywnego leczenia lub indywidualnego podejścia do planu leczenia z np. podwyższeniem dawki na ten obszar. Analizą tego zagadnienia zajął się zespół z Austrii w pracy „Biological treatment response and hypoxia monitoring of cervix cancer using multiparametric $3 T-M R I$ and 18F-FMISO". U chorych wykonywano zarówno przed leczeniem, a także 2 tygodniu i 5 tygodniu w trakcie leczenia i 3 m-ce po leczeniu badanie FMISO PET/CT i multiparametryczne badanie rezonansem magnetycznym (MPMRI). Lekarz specjalista radioterapii onkologicznej wyznaczał na podstawie badań obszar tarczowy GTV (ang. gross tumor volume). Analizie poddano następujące parametry: dyfuzja, wielkość, kinetyka SUV max F-MISO. Zaobserwowano morfologiczne i funkcjonalne zmiany w dyfuzji, perfuzji i hipoksji guza. Stwierdzono zmniejszenie objętości GTV kolejno: 43,9cc przed leczeniem, 22,4cc po 2tyg (20-25Gy) i 7,7cc po 5tyg (40-45Gy); wzrost średniej ADC /rzeczywisty współczynnik dyfuzji/: 1.02x10$3 \mathrm{~mm} 2 / \mathrm{sec}$ przed leczeniem, $1,18 \times 10-3 \mathrm{~mm} 2 / \mathrm{sec}$ po 2 tyg i $1,27 \times 10-3 \mathrm{~mm} 2 / \mathrm{sec}$ po 5 tyg i $1,37 \times 10-3 \mathrm{~mm} 2 / \mathrm{sec}$ po 3 m-cach; spadek wartości SUV-norm 18F-FMISO: 3.1 przed leczeniem, 2,3 po 2tyg i 2,0 po 5tyg leczenia.

Praca z Wielkiej Brytanii „Defining a standard method for functional bone marrow sparing with IMRT 
for cervical cancer" przedstawiła zastosowanie planowania leczenia metodą IMRT celem zaoszczędzenia aktywnie metabolicznego szpiku kostnego zobrazowanego w badaniu FDG PET. W ten sposób możliwe było zredukowanie hematologicznej toksyczności podczas radiochemioterapii. Określono powtarzalny wzór aktywnego metabolicznie szpiku stosując SUV 75\%. Zdefiniowano ponadto najwyższą aktywność metaboliczną u pacjentek, która występuję w odcinku lędźwiowym, krzyżowym, tylnej części skrzydeł kości biodrowej i w kości łonowej. Regiony te obejmują 86,67\% całkowitej aktywności, stanowią 6,9\% całkowitej objętości miednicy. Następnie zastosowano leczenie radioterapeutyczne z oszczędzeniem tych rejonów. Dzięki temu spodziewany jest zysk w hematologicznej toksyczności podczas radiochemioterapii [21]. Toczy się także badanie RTOG 0418, które ma na celu zdefiniowanie obszarów z aktywnym szpikiem kostnym w obrębie miednicy.

\section{Podsumowanie}

Rola badania FDG PET-CT jest już ugruntowana i poparta wieloma doniesieniami naukowymi. Obecne badanie GOG 233/ACRIN 6671 prowadzone we współpracy National Cancer Institute (NCI) i Gynecologic Oncology Group (GOG) American College of Radiology Imaging Network (ACRIN) ma na celu raz jeszcze potwierdzić rolę PET-CT w ocenie rozsiewu węzłowego chorych z rozpoznanym rakiem szyjki macicy. Liczne zastosowania tego badania obejmują ocenę wczesną i monitorowanie odpowiedzi w okresie follow-up, poszukiwanie chorych nie odpowiadających na zastosowane leczenie, ocenę statusu węzłowego i zaawansowania w kontekście przerzutów odległych. To przyczynia się do precyzyjnego ustalenia zaawansowania i zmiany podejścia terapeutycznego. Ponadto zastosowanie badania PET jest niezbędne by zdefiniować objętości tarczowe, a jednocześnie zaplanować leczenie z zaoszczędzeniem aktywnego metabolicznie szpiku. Zrozumienie mikrośrodowiska guza np. neoangiogenezy, proliferacji czy hipoksji otwiera drogę do zastosowania w przyszłości innowacyjnych molekularnych technik leczenia.

\section{Konflikt interesu / Conflict of interest}

Nie występuje / None

\section{Etyka / Ethics}

Treści przedstawione w artykule są zgodne z zasadami Deklaracji Helsińskiej, dyrektywami EU oraz ujednoliconymi wymaganiami dla czasopism biomedycznych.

\section{Piśmiennictwo / References}

[1] Ferlay J, Bray F, Pisani P, Parkin DM Cancer incidence, mortality and prevalence worldwide. IARC CancerBase No. 5 [CD-ROM]. Version 1.1. Lyon: IARC Press; 2001. GLOBOCAN 2000

[2] Krzakowski M, Warzocha K. Zalecenia postępowania diagnostyczno-terapeutycznego w nowotworach złośliwych 2013 rok. Onkologia w Praktyce Klinicznej.2013;9 (supl. B).

[3] Krajowy Rejestr Nowotworów - Raporty na podstawie danych Centrum Onkologii. Warszawa: Zakład Epidemiologii i Prewencji Nowotworów Centrum Onkologii w Warszawie; 2013 [cited 16-11-2014]; Available from: http://85.128.14.124/krn/

[4] Grigsby PW1, Siegel BA, Dehdashti F. Lymph node staging by positron emission tomography in patients with carcinoma of the cervix. Int J Radiat Oncol Biol Phys. 2004 Mar 15;58(4):1289-97.

[5] Esthappan J1, Mutic S, Malyapa RS, Grigsby PW, Zoberi I, Dehdashti F, Miller TR, Bosch WR, Low DA.Treatment planning guidelines regarding the use of CT/PET-guided IMRT for cervical carcinoma with positive paraaortic lymph nodes. Eur J Radiol. 2011 Apr;78(1):12-20. doi: 10.1016/j.ejrad.2009.12.035.

[6] Musto A1, Rampin L, Nanni C, Marzola MC, Fanti S, Rubello D. Present and future of PET and PET/CT in gynaecologic malignancies. J Natl Compr Canc Netw. 2013 Mar 1;11(3):320-43.

[7] Yeh LS1, Hung YC, Shen YY, Kao CH, Lin CC, Lee CC. Detecting para-aortic lymph nodal metastasis by positron emission tomography of $18 \mathrm{~F}$-fluorodeoxyglucose in advanced cervical cancer with negative 
magnetic resonance imaging findings. Oncol Rep. 2002 Nov-Dec;9(6):1289-92.

[8] Lin WC1, Hung YC, Yeh LS, Kao CH, Yen RF, Shen YY. Usefulness of (18)F-fluorodeoxyglucose positron emission tomography to detect para-aortic lymph nodal metastasis in advanced cervical cancer with negative computed tomography findings. J Clin Oncol. 1999 Jan;17(1):41-5.

[9] Rose PG1, Adler LP, Rodriguez M, Faulhaber PF, Abdul-Karim FW, Miraldi F. Positron emission tomography for evaluating para-aortic nodal metastasis in locally advanced cervical cancer before surgical staging: a surgicopathologic study. J Clin Oncol. 1999 Jan;17(1):41-5.

[10] Michael J. Reinhardt, MD, , Claudia Ehritt-Braun, MD, , Dagmar Vogelgesang, MD, Christian Ihling, MD, Stefan Högerle, MD, Michael Mix, MSc, Ernst Moser, MD, PhD, and, Thomas M. Krause, MD Metastatic Lymph Nodes in Patients with Cervical Cancer: Detection with MR Imaging and FDG PET.

[11] Tarik Belhocine, M.D.,Alain Thille, M.D., Viviana Fridman, M.D., Adelin Albert, Ph.D., Laurence Seidel, M.Sc.,§ Philippe Nickers, M.D., Frederic Kridelka, M.D., and Pierre Rigo, M.D.*Contribution of WholeBody 18FDG PET Imaging in the Management of Cervical Cancer. Gynecologic Oncology 87, 90 -97 (2002)

[12] Perez \& Brady's Principles and Practice of Radiation Oncology, 6e, By Edward C. Halperin, Luther W. Brady, Carlos A. Perez and David E. Wazer

[13] Grigsby PW, Siegel BA, Dehdashti F, et al. Posttherapy surveillance monitoring of cervical cancer by FDG-PET. Int $J$ Radiat Oncol Biol Phys 2003;55:907-913

[14] Grigsby PW, Siegel BA, Dehdashti F, et al. Posttherapy [18F] fluorodeoxyglucose positron emission tomography in carcinoma of the cervix: response and outcome. J Clin Oncol 2004;22:2167-2171

[15] Kidd EA, Spencer CR, Huettner PC, et al. Cervical cancer histology and tumor differentiation affect 18F-fluorodeoxyglucose uptake. Cancer 2009;115:3548-355

[16] Sahar Mirpour ${ }^{1}$, Joyce C. Mhlanga ${ }^{1}$, Prashanti Logeswaran2, Gregory Russo3, Gustavo Mercier2 and Rathan M. Subramaniam1, The Role of PET/CT in the Management of Cervical Cancer2Review, 2013

[17] Belhocine T, Thille A, Fridman V, et al. Contribution of whole-body 18FDG PET imaging in the management of cervical cancer. Gynecol Oncol 2002;

[18] Francis DL, et al.Assessment of recurrent colorectal cancer following 5-fluorouracil chemotherapy using both 18FDG and 18FLT PET. Eur J Nucl Med Mol Imaging 2004

[19] Been LB, Suurmeijer AJ, Cobben DC, Jager PL, Hoekstra HJ, Elsinga PH 2004. [18F]FLT-PET in oncology: current status and opportunities. Eur J Nucl Med Mol Imaging 31: 1659-72

[20] E. Burchardt, P. Cegla, A. Roszak, W. Cholewinski Comparison of 18F-FLT PET and 18F-FDG PET in the radiotherapy treatment of cervical cancer. Radiotherapy and Oncology April 2015Volume 115, Supplement 1, Pages S215-S216

[21] Klopp AH1, Moughan J, Portelance L, Miller BE, Salehpour MR, Hildebrandt E, Nuanjing J, D’Souza D, Souhami L, Small W Jr, Gaur R, Jhingran A. Hematologic toxicity in RTOG 0418: a phase 2 study of postoperative IMRT for gynecologic cancer. 2013 